\title{
A Teoria de Metodologia Ativa na Prática: uma Vivência entre Pós-Graduandos e Graduandos numa Atividade Extraclasse
}

\section{Active Learning in Practice: An Experience Between Graduate and Undergraduate Students in an Extra-Class Activity}

\author{
Gabriel Pereira Gouveia da Silva1, João Paulo Eguea, Kandice Suane Barros Ribeiro, Luciana \\ Montanari ${ }^{1 *}$
}

${ }^{1}$ Escola de Engenharia de São Carlos da Universidade de São Paulo

* Autora para correspondência: montanar@sc.usp.br

\begin{abstract}
RESUMO
As metodologias ativas de ensino apresentam técnicas de ensino-aprendizagem baseadas na construção ativa de conhecimento, com foco no estudante. A formação de pós-graduandos e novos docentes capazes de utilizar tais metodologias se faz necessária no cenário atual do ensino superior. O conceito de Metodologia Ativa foi apresentado aos estudantes de Pós-Graduação na disciplina de Preparação Pedagógica oferecida no Programa de Pós-Graduação em Engenharia Mecânica da Escola de Engenharia de São Carlos (PPGEM-EESC-USP). Para colocar em prática as metodologias apresentadas, sugeriu-se a participação dos pós-graduandos como mediadores de conhecimento em uma atividade extraclasse da disciplina de Desenho Técnico Mecânico I (DTM I), oferecida aos estudantes do curso de graduação em Engenharia Mecânica da EESC-USP. A atividade foi desenvolvida durante quatro semanas consecutivas, contando com a participação voluntária de quatro pósgraduandos e catorze estudantes de graduação. $\mathrm{O}$ desempenho dos estudantes de graduação participantes das atividades melhorou em relação à prova anterior e também foi superior ao desempenho médio de todos os alunos da turma. Do ponto de vista dos pós-graduandos, a atividade permitiu uma experiência de planejar e executar um plano de aula que fizesse uso de metodologias ativas em sala. Os resultados acadêmicos dos alunos de graduação e o relato dos pós-graduandos mostram como tais atividades são uma forma de melhoria do ensino e aprendizagem, com destaque para o benefício proporcionado pela integração entre alunos de graduação e de pós-graduação no contexto da formação de novos docentes.
\end{abstract}

Palavras-Chave: Metodologia Ativa; Ensino e Aprendizagem; Desenho Técnico Mecânico.

\begin{abstract}
Active learning methods are techniques based on the active construction of knowledge, focusing on the student. The education of graduate students to be teachers that will able to use such methods is necessary in the current scenario of higher education. The concept of active learning was presented to the graduate students in the Pedagogical Preparation course, offered by the Graduate Program in Mechanical Engineering of the São Carlos School of Engineering (PPGEM-EESC-USP). To put the presented methodologies into practice, the graduate students were invited to act as knowledge mediators in an extra-class activity for the Mechanical Engineering Drawing I course (DTM I), offered to undergraduate students in Mechanical Engineering at EESC- USP. The activity was developed for 4 consecutive weeks, with the voluntary participation of 4 postgraduate students and 14 undergraduate students. The performance of undergraduate students participating in the activities improved when compared to the previous test and was also superior to the average performance of all students in the class. From the perspective of graduate students, the activity provided an experience of planning and executing a lesson plan based on active learning methods. The academic results of undergraduate students and the report of graduate students show how such activities are a way of improving teaching and learning, highlighting the benefit provided by the integration between undergraduate and postgraduate students in the context of training future higher education teachers.
\end{abstract}

Keywords: Active Learning; Teaching and Learning; Mechanical Engineering Drawing. 


\section{Contextualização}

$\mathrm{O}$ modelo atual de ensino das universidades brasileiras, em sua maioria, se baseia em um modelo tradicional de ensino, cujas características remontam às metodologias de ensino baseadas no modus parisiensis, empregadas inicialmente há cerca de quinhentos anos pelos colégios e universidades jesuítas e posteriormente reforçadas pela importação do modelo universitário napoleônico (ANASTASIOU, 2001).

Segundo Anastasiou (2001), nesse modelo:

O conhecimento é tomado como algo posto, indiscutível, pronto e acabado e, consequentemente, deve ser assim repassado, usando-se a memorização como operação essencial do processo de aprendizagem e recurso básico do ensino. Destacam-se: a figura do professor repassador desse conteúdo indiscutível a ser memorizado; o modelo da exposição (aula expositiva - quase palestra) acompanhado de exercícios a serem resolvidos pelos alunos; a avaliação/emulação/castigos; o controle rígido e pré-estabelecido universalmente (independente de características nacionais, regionais, ou de clientela); a manutenção do modelo único por controle rígido dentro e fora da sala de aula; a hierarquia de organização de estudos; um aluno passivo e obediente, que memoriza o conteúdo para a avaliação - enfim, uma estrutura rígida de funcionamento do processo de ensino-aprendizagem: um modelo que acaba de completar quinhentos anos!

Tal método vem se mostrando inefetivo e desmotivante, principalmente nos cursos de Engenharia, fatos evidenciados pelo alto número de reprovações e evasão dos cursos. Segundo informações do parecer homologado pelo Ministério da Educação em 23 de abril de 2019, que trata das novas diretrizes curriculares nacionais para os cursos de graduação em Engenharia, de cada mil candidatos inscritos em cursos de Engenharia, 18\%, em média, ingressam nos cursos e apenas $54 \%$ dos ingressantes concluem o curso (BRASIL, 2019). Em uma análise bibliométrica de trabalhos publicados no Congresso Brasileiro de Educação em Engenharia (Cobenge) no período de 2000 a
2014, Godoy e Almeida (2017) mostram que as questões pedagógicas são as principais causas de evasão nos cursos de Engenharia, sobressaindo as expressões-chave "Reprovações sucessivas nas disciplinas", "Estrutura curricular" e "Metodologia didático-pedagógica dos professores" como as mais recorrentes nos artigos. Os fatores pedagógicos também foram os mais citados como solução para o problema de evasão, estando as expressões-chave "Melhoria das ferramentas computacionais no processo de ensino e aprendizagem", "Reestruturação curricular", "Trabalho em equipe para incentivar a integração do corpo discente" e "Implantação de metodologias de aprendizagem ativas" entre as mais citadas nessa categoria. Tais dados alarmantes mostram a necessidade de uma reinvenção do sistema universitário e dos métodos de ensino. Essa necessidade poderá ser suprimida ou modificada com a implantação das novas diretrizes curriculares para os cursos de Engenharia.

Quando se trata do ensino de Engenharia, a aplicação de novas metodologias de ensino ainda é tímida em relação ao número de disciplinas oferecidas, embora um grande número de estudos e relatos de experiência no assunto sejam encontrados na literatura (BARBOSA \& MOURA, 2014; BARDINI \& SPALDING, 2017; BRUM, PURCIDONIO \& FERREIRA, 2017; PARREIRA, 2017). Parte fundamental para a maior adoção de metodologias ativas (MAs) em sala de aula é o estudo do tema dentro da universidade e a preparação dos pós-graduandos para sua aplicação. Sem a inclusão dessa temática na formação de mestres e doutores, cria-se espontaneamente um ambiente propício para a reprodução e a manutenção de uma ação docente baseada no conceito de ensinar estabelecido pelo senso comum: a metodologia tradicional na qual os pós-graduandos estiveram imersos durante toda sua formação, desde o ensino fundamental à graduação (ANASTASIOU, 2001). Dessa forma, disciplinas de preparação pedagógica que forneçam um espaço para discussão, aquisição e implementação de um novo repertório de ferramentas educacionais são essenciais para a melhoria do ensino e a aprendizagem nas universidades. 


\section{Metodologia}

Nesse contexto, foi proposto o desenvolvimento de uma atividade em que os alunos de pós-graduação, cursando a disciplina de Preparação Pedagógica, atuassem como mediadores de conhecimento em uma atividade extraclasse da disciplina de Graduação, Desenho Técnico Mecânico I (DTM I), oferecida aos alunos do curso de graduação em Engenharia Mecânica da EESC-USP.

Os assuntos, objetos da aula, foram abordados de modo tradicional pela professora responsável e foram, posteriormente, trabalhados pelos alunos da pós-graduação, empregando metodologias ativas. Essas atividades ocorreram fora do horário regular de aula. Os planos de aula e materiais utilizados nessas atividades foram idealizados, elaborados, organizados e obtidos pelos pós-graduandos. Para o desenvolvimento da atividade os pós-graduandos buscaram vídeos e imagens em sites da internet e peças e conjuntos mecânicos disponíveis nos laboratórios da EESC. No total quatro pós-graduandos e catorze alunos de graduação participaram como voluntários em quatro atividades distintas sobre tópicos diferentes com o acompanhamento da professora responsável. Essas atividades encontram-se detalhadas no quadro 1. Cada pós-graduando ficou responsável pela idealização e preparação de uma única atividade. No entanto, os quatro pós-graduandos participaram de todas as atividades extras, sendo que o responsável pela atividade a conduzia, enquanto os demais atuavam como monitores, tirando dúvidas dos graduandos durante as práticas.

A figura 1(a) mostra as peças que compõem o redutor usado nas atividades 1,2 e 3 , enquanto a figura 1(b) ilustra a interação entre os alunos de graduação e pós-graduação durante a atividade 4 .

\begin{tabular}{|c|c|c|}
\hline Atividade & Material & Descrição \\
\hline $\begin{array}{l}1 \text { - Elementos } \\
\text { de } \\
\text { Transmissão }\end{array}$ & $\begin{array}{l}\rightarrow \text { Fotos e vídeos (projetor) } \\
\rightarrow \text { Redutor (Figura 1(a)) } \\
\rightarrow \text { Paquímetro } \\
\rightarrow \text { Engrenagens } \\
\rightarrow \text { Caixa de câmbio manual }\end{array}$ & $\begin{array}{l}\rightarrow \text { Exibição de fotos e vídeos de diferentes sistemas } \\
\text { de transmissão. } \\
\rightarrow \text { Exibição ao vivo e contato dos alunos com um } \\
\text { conjunto mecânico de redutor e uma caixa de câmbio } \\
\text { manual. } \\
\rightarrow \text { Desenho de observação do redutor a partir de } \\
\text { medidas feitas com paquímetro, com discussão em } \\
\text { grupo. }\end{array}$ \\
\hline $\begin{array}{l}2 \text { - Elementos } \\
\text { de União }\end{array}$ & $\begin{array}{l}\rightarrow \text { Fotos (projetor) } \\
\rightarrow \text { Parafusos, porcas, arrue- } \\
\text { las, rebites, cupilhas, pinos, } \\
\text { cavilhas, anéis elásticos e } \\
\text { chavetas } \\
\rightarrow \text { Redutor (Figura } 1(\mathrm{a}) \text { ) } \\
\rightarrow \text { Paquímetro }\end{array}$ & $\begin{array}{l}\rightarrow \text { Exibição ao vivo de diferentes elementos de união } \\
\text { e das representações gráficas correspondentes. } \\
\rightarrow \text { Desenho de observação de peças de união do } \\
\text { redutor (união eixo-cubo por chaveta, união por pa- } \\
\text { rafusos da carcaça e anéis elásticos nos eixos) a partir } \\
\text { de medidas feitas com paquímetro, com discussão em } \\
\text { grupo. }\end{array}$ \\
\hline $\begin{array}{l}3 \text { - Elementos } \\
\text { de Apoio }\end{array}$ & $\begin{array}{l}\rightarrow \text { Fotos (projetor) } \\
\rightarrow \text { Redutor (Figura 1(a)) } \\
\rightarrow \text { Paquímetro } \\
\rightarrow \text { Lousa e giz }\end{array}$ & $\begin{array}{l}\rightarrow \text { Exibição de fotos de diferentes elementos de apoio } \\
\text { (buchas, guias, mancais, rolamentos, molas, juntas, } \\
\text { retentores e anéis o'ring) e da representação gráfica } \\
\text { correspondente. } \\
\rightarrow \text { Montagem e desmontagem de um redutor, identi- } \\
\text { ficando os elementos de apoio e seu posicionamento. } \\
\rightarrow \text { Complementação do desenho desenvolvido na } \\
\text { atividade } 1 \text {, adicionando os elementos de apoio ne- } \\
\text { cessários. } \\
\rightarrow \text { Desenho na lousa, avaliado e discutido pela turma. }\end{array}$ \\
\hline
\end{tabular}




\begin{tabular}{|c|c|c|}
\hline Atividade & Material & Descrição \\
\hline \multirow[t]{2}{*}{4 - Solda } & \multirow{2}{*}{$\begin{array}{l}\rightarrow \text { Fotos e vídeos (projetor) } \\
\rightarrow \text { Cartões contendo dese- } \\
\text { nhos de soldas para o jogo } \\
\text { de "telefone sem fio" } \\
\rightarrow \text { Lousa e giz }\end{array}$} & $\begin{array}{l}\rightarrow \text { Exibição de fotos e vídeos de diferentes tipos de sol- } \\
\text { da e processos de soldagem e da representação gráfica } \\
\text { correspondente. }\end{array}$ \\
\hline & & $\begin{array}{l}\rightarrow \text { Jogo de telefone sem fio na lousa (ver descrição da } \\
\text { atividade no Relato } 1 \text { ) }\end{array}$ \\
\hline
\end{tabular}

Quadro 1 - Detalhamento das atividades extraclasse elaboradas pelos pós-graduandos.

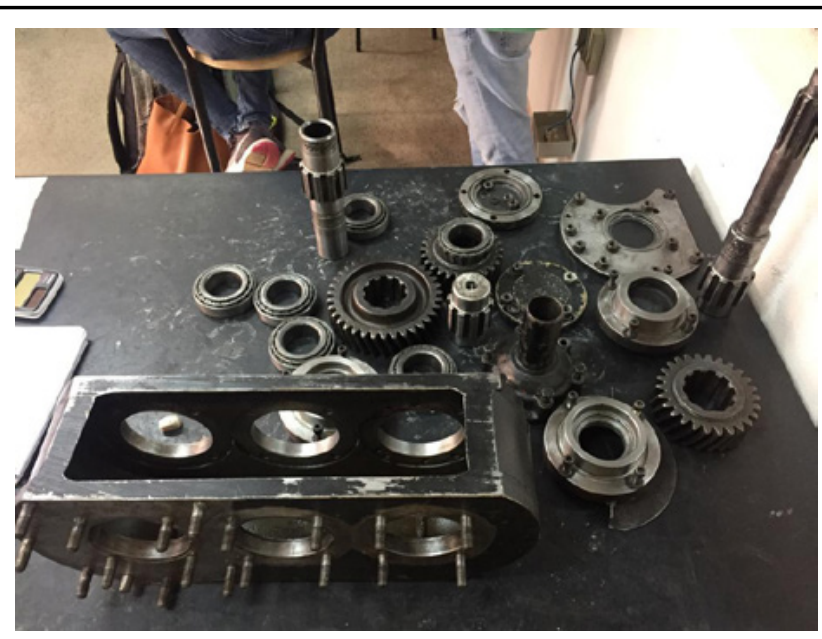

(a) Componentes do redutor usado nas atividades 1,2 e 3 .

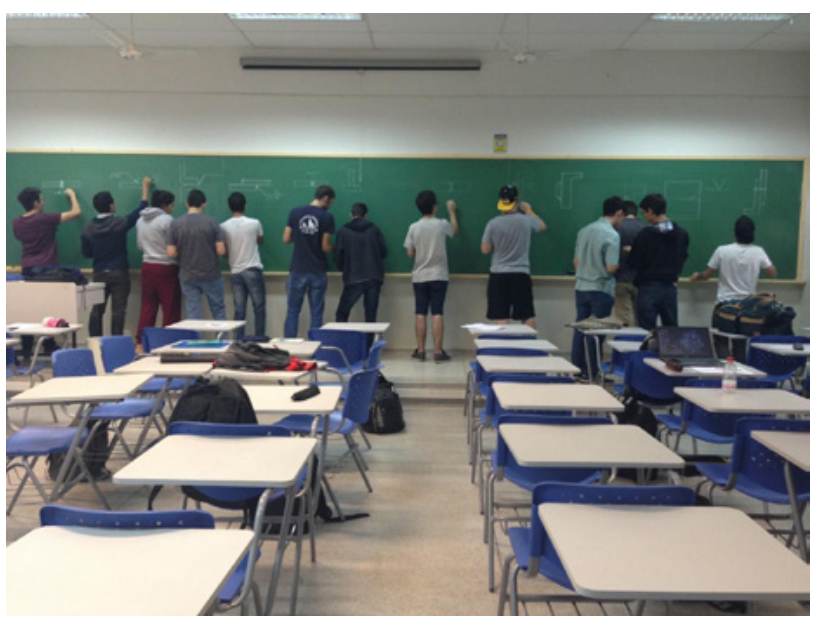

(b) Atividade sobre simbologia e representação de juntas soldadas (atividade 4)

Figura 1 - Ilustração das atividades 1, 2, 3 e 4 .

O desempenho dos alunos que participaram da atividade foi comparado com o desempenho dos alunos que não participaram. $\mathrm{O}$ rendimento foi mensurado através de notas atribuídas em duas avaliações (anterior e posterior às atividades extraclasse). Essa atividade também implicou a formação dos pós-graduandos envolvidos. A experiência dos pós-graduandos aparece em forma de relatos.

\section{Resultados}

Os resultados foram divididos em duas partes, uma com relação ao desempenho na avaliação dos alunos de graduação e o relato dos pós-graduandos.

\section{Alunos de Graduação}

O desempenho dos alunos em DTM I é mostrado na tabela 1 , sendo divididos nas duas avaliações (do tipo prova) e nos grupos que participaram ou não da atividade extraclasse.
Os alunos participantes da atividade apresentaram melhor rendimento na primeira avaliação (anterior à aplicação de metodologias ativas em atividade extraclasse), se comparado ao dos alunos que não participaram da atividade. Observando a tabela 1 , nota-se que os alunos que participaram da atividade mantiveram melhor rendimento em relação aos alunos que não participaram e, além disso, há aumento de nota. Por outro lado, os alunos que não participaram da atividade apresentam redução de nota. É evidente que os participantes apresentaram maior interesse em aprender, uma vez que a atividade era facultativa e os mesmos participaram de todas as atividades. Além disso, a atividade também serviu como revisão dos conteúdos, auxiliando na aprendizagem dos conceitos trabalhados.

Houve outras avaliações na disciplina além das provas apresentadas na tabela 1 , tais como três entregas de desenhos técnicos de peças com datas 


\section{Média Avaliação 1 (antes da Média Avaliação 2 (após a atividade) atividade)}

Alunos que não

participaram da

atividade (18 alunos)
5,2

4,7
Alunos que participaram da atividade (14 alunos)
6,3

Tabela 1 - Média dos Alunos nas Avaliações.

previamente estabelecidas e um trabalho final, em que foram cobrados os desenhos de conjunto e de componentes de um dado conjunto mecânico. Portanto, essa média não reflete a nota final do aluno ou a aprovação ou não na disciplina, mas indica que a aplicação de metodologias ativas auxilia na aprendizagem e, consequentemente, no rendimento das avaliações.

\section{Pós-Graduandos}

Os pós-graduandos participantes foram convidados a redigir um relato sobre a experiência de elaborar e ministrar uma aula aplicando metodologias ativas. Os textos daqueles que contribuíram são reproduzidos a seguir.

\section{Relato 1}

De início a proposta de aplicar MAs parecia incompativel com o tema da representação de soldas em DTM. Porém, partindo-se da ideia de que DTM é uma linguagem de comunicação, surgiu a ideia de implementar uma Aprendizagem Baseada em Jogos, inspirando-se no jogo popular "telefone sem fio", que explora falhas de comunicação. No jogo original, uma mensagem falada é transmitida através de uma cadeia de pessoas e o objetivo é obter ao final o mínimo de distorção na mensagem original. No jogo adaptado, uma determinada junta soldada seria apresentada a um aluno, que deveria então desenhar para outro aluno a representação gráfica normatizada daquela solda, aprendida na aula regular e reforçada na aula extra. Por fim, um terceiro aluno deveria desenhar a união soldada original a partir da representação técnica feita pelo segundo aluno. Assim, os alunos puderam exercitar de maneira lúdica os conceitos de DTM, além de verificar a importância das normas de desenho na comunicação que se pretende estabelecer entre os profissionais da área. A atividade promoveu a discussão entre os alunos, os monitores e a professora, com destaque para o impacto que uma má comunicação técnica por falta de dominio das normas pode ter num ambiente de trabalho, onde erros desta natureza podem levar a prejuizos. Além do jogo, considerei minha própria experiência enquanto aluno de graduação quando cursei a disciplina, e elaborei um material onde ilustrei com vídeos e fotografias os mais variados tipos de solda que em geral só são apresentados por nomes, descrições verbais e através de desenhos. Este material foi apresentado antes da execução do jogo. Sua elaboração, além de me permitir aprender informacõoes novas e fixar melhor conteúdos que eu já havia visto anos antes, também aumentou a motivação dos alunos para o tema, uma vez que o assunto foi apresentado de maneira mais visual, concreta e próxima da realidade.

Dar a aula foi uma experiência interessante: ao mesmo tempo empolgante por sentir quando os alunos compreendiam algo que antes não havia ficado claro, e desmotivante quando os alunos dispersavam ou não demonstravam interesse na aula. No geral, percebi que os alunos inicialmente estavam desconfiados e desconfortáveis com as MAs aplicadas, mas que, conforme se engajavam mais com a atividade, passavam a mostrar interesse e dedicação. Para mim, a realização desta atividade contribuiu muito na minha experiência e formação como docente. $O$ desafio de sair da zona de conforto estabelecida pelas metodologias tradicionais mostrou-se valioso, embora trabalhoso, pois 
ao mesmo tempo em que consegui aprender melhor os próprios conteúdos lecionados, também pude perceber um maior engajamento e interesse dos alunos na temática trabalhada em sala de aula. Atualmente, como estagiário PAE e professor voluntário em um curso pré-vestibular, tenho aplicado as MAs nas disciplinas em que leciono, o que tem mostrado resultados positivos entre os alunos, e pretendo seguir implementando e aprimorando essas $M A s$ ao longo de minha carreira. Portanto, a experiência das atividades extraclasse aqui relatadas foi essencial para que eu me iniciasse nestas metodologias, sentindo na prática o quanto elas podem fazer a diferença na vida do professor $e$ dos alunos.

\section{Relato 2}

No contexto atual de ensino em engenharia, empregar metodologias facilitadoras do aprendizado e que mantenham os alunos engajados é desafiador. Vejo isso por dois principais motivos: a forma com que aprendemos, baseada em metodologias passivas, e nosso desejo de mudar, de facilitar a passagem do conteúdo aos alunos, de forma que eles se sintam encorajados e vejam aplicação da base que aprendem. Acredito que somos parte de uma geração de transição no ensino em engenharia.

Esse primeiro contato com alunos de graduação de engenharia mecânica me permitiu aplicar um pouco da teoria vista na disciplina de preparação pedagógica. Preparar aulas com base nas melhores experiências que tive como discente, evitar repetir experiências não tão boas, foi o início para estruturar a exposição do conteúdo. No planejamento, apliquei metodologias ativas, como uso de vídeo $e$ atividades práticas, incentivando os alunos a aprender com a prática, enquanto viam aplicações diretas do que estariam produzindo. DTM, ao meu ver, é uma disciplina fundamental para todo engenheiro.

$O$ primeiro contato com a turma foi rápido. Enquanto nos acostumávamos uns com os outros, sensações de frio na barriga e algumas perguntas vieram: Será que estou fazendo certo? O que estão pensando agora? Estou indo rápido ou devagar demais? Como eles reagirão a essa atividade? Quanto tempo dou para que eles finalizem?

Com a experiência, aprendi que, na caminhada do conhecimento, ter esse sentimento de feedback, conhecer os alunos e como eles aprendem melhor, como motivá-los e como despertar interesse é importante e requer dedicação deles, tendo compromisso mútuo com o aprendizado. De um lado, docentes dedicados em proporcionar o melhor entendimento possível na transferência do conhecimento, de forma adequada ao público; do outro, alunos motivados e interessados em ter esse conhecimento.

Depois dessa aula, fiz três estágios PAE e ministrei um minicurso. Com o tempo notei que o frio na barriga vem diminuindo, as metodologias ativas, adaptar o conteúdo ao público-alvo, ao conhecimento e às particularidades de cada um dos alunos são cada vez mais naturais no planejamento da aula. Vejo-me cada vez mais no caminho da docência. Poder transmitir o conhecimento e facilitar o aprendizado me motiva e me completa como profissional.

\section{Relato 3}

Durante o curso tive meu primeiro contato com as metodologias ativas. Elas me chamaram a atenção por combinarem com as disciplinas da graduação, embora a esmagadora maioria dos professores utilize a metodologia tradicional, com aulas expositivas e slides. Surgiu então a questão do porquê de as metodologias ativas não serem utilizadas amplamente na graduação em Engenharia. A atividade trouxe a oportunidade de ter uma experiência em sala de aula e aplicar esses métodos. Foi proposto que eu desenvolvesse uma aula abordando o conteúdo sobre rolamentos na disciplina de DTM I para o $1^{\circ}$ ano em Engenharia Mecânica. No início ocorreu um choque: como aplicar metodologias ativas para um conteúdo focado em normas técnicas de que tive dificuldade na graduação? Tive ideias conversando com os colegas e a Prof. Luciana. A atividade contava com a exposição das normas de desenho para rolamentos e molas. Levamos para a sala um redutor para que os alunos vissem como os componentes são utilizados, contextualizando a matéria com as aplicações presentes na vida profissional. Mexer nas peças e verificar o trabalho de montagem permitiram aos alunos entender a função e posicionamento de componentes; e conceitos de ajuste e tolerância, que parecem distantes e irreais quando expostos em uma aula com slides. Ver o componente permitiu que eles entendessem como as normas de DTM representam o elemento real. A sensação dos alunos era de prazer por conseguirem visualizar o que fora exposto em aula e no início da atividade. $A$ atividade também me permitiu entender e aprofundar conceitos que não foram bem fixados em meu curso de DTM na graduação, criando um ambiente de identificação e aprendizado mútuo. No final, os alunos desenharam os 
componentes da montagem, alguns na lousa para que os colegas avaliassem se o desenho estava de acordo com as normas de DTM. O impacto nas notas foi extremamente gratificante.

$A$ atividade foi fundamental no meu desenvolvimento como futuro professor, despertando ainda mais meu desejo de seguir na carreira e aplicar metodologias ativas em meus estágios PAE. Através dela soube do Congresso de Graduação, do qual participei em 2018 e 2019. O evento trouxe uma visão de aplicações de novos métodos de ensino e seu impacto no aprendizado. Metodologias ativas aproximam professor e aluno, rompem barreiras e tornam o aluno protagonista do aprendizado, construindo o saber de forma significativa para si.

\section{Conclusões}

Pela comparação de notas entre a primeira e a segunda avaliações e entre as notas dos participantes e não participantes da atividade, é possível afirmar que a atividade teve êxito e também indica que a aplicação de metodologias ativas no processo de aprendizagem contribui de maneira eficiente no desempenho do estudante e em suas motivações para aprender. Com relação aos pós-graduandos, eles foram criativos no desenvolvimento de suas atividades, responsáveis com o conteúdo e verificaram que, quando os alunos se sentem protagonistas de seu aprendizado, todo o processo fica mais agradável e que a aplicação de metodologias ativas pode ocorrer a qualquer momento do curso e em qualquer disciplina. Para tanto, basta encontrar a metodologia que se adeque à disciplina e desenvolvê-la com responsabilidade.

A apresentação e o desenvolvimento de atividades relacionadas com metodologias ativas durante a disciplina Preparação Pedagógica se tornaram excelentes oportunidades para proporcionar experiência aos pós-graduandos e avaliar o impacto dessas metodologias na aprendizagem dos estudantes de graduação.

\section{Referências Bibliográficas}

ANASTASIOU, Léa das Graças Camargos. "Metodologia de Ensino na Universidade Brasileira: Elementos de uma Trajetória". In: CASTANHO, Sérgio \& CASTANHO, Maria Eugênia (orgs.). Temas $e$ Textos em Metodologia do Ensino Superior. Campinas: Papirus, 2001.

GODOY, Elenilton Vieira; ALMEIDA, Eustáquio de. "A Evasão nos Cursos de Engenharia e a Sua Relação com a Matemática: uma Análise a partir do Cobenge". Educasãa Matemática Debate, [s.l.], vol. 1, n. 3, 2017, pp. 339-348.

BARBOSA, Eduardo Fernandes \& MOURA, Dácio Guimarães. "Metodologias Ativas de Aprendizagem no Ensino de Engenharia". In: Anais International Conference on Engineering and Technology Education. Cairo, 2014.

BARDINI, VivianSilveiradosSantos\&SPALDING, Marianne. "Application of Active Teaching-Learning Methodologies: Experience in the Engineering Area". Revista de Ensino de Engenharia, [s.1.], vol. 36, n. 1, 2017, pp. 49-58. GN1 Genesis Network. Disponível em: $<$ http://dx.doi.org/10.5935/2236-0158.20170005>.

BRASIL. Ministério da Educação. Diretrizes Curriculares Nacionais do Curso de Graduação em Engenharia. Parecer CNE/CES 1/2019, homologação publicada no DOU 23/04/2019, Seção 1, p. 109.

BRUM, Karina Fernandes; PURCIDONIO, Paula Michelle \& FERREIRA, Marta Lucia Azevedo. "Aprendizagem Ativa no Ensino de Engenharia de Métodos: uma Experiência no Cefet/RJ". Revista Produção Online, [s.l.], vol. 17, n. 3, 15 set. 2017, pp. 956-974. Associação Brasileira de Engenharia de Produção - Abepro. Disponível em: <http://dx.doi. org/10.14488/1676-1901.v17i3.2739>.

PARREIRA, J. E. "Aplicação e Avaliação de uma Metodologia de Aprendizagem Ativa (Tipo ISLE) em Aulas de Mecânica, em Cursos de Engenharia". Revista Brasileira de Ensino de Física, [s.l.], vol. 40, n. 1, e1401, 20 jul. 2017, pp. 1-6. Fap-UNIFESP (SciELO). Disponível em: <http://dx.doi. org/10.1590/1806-9126-rbef-2017-0180>.

Publicado em 28/07/2020. 